\title{
Phosphorylated cellulose nanofibers exhibit exceptional capacity for uranium capture
}

\author{
Janika Lehtonen · Jukka Hassinen • Avula Anil Kumar • Leena-Sisko Johansson • \\ Roni Mäenpää · Nikolaos Pahimanolis • Thalappil Pradeep • Olli Ikkala • \\ Orlando J. Rojas $\mathbb{D}$
}

Received: 30 November 2019/ Accepted: 2 January 2020/Published online: 13 January 2020

(C) The Author(s) 2020

\begin{abstract}
We investigate the adsorption of hexavalent uranium, $\mathrm{U}(\mathrm{VI})$, on phosphorylated cellulose nanofibers (PHO-CNF) and compare the results with those for native and TEMPO-oxidized nanocelluloses. Batch adsorption experiments in aqueous media show that PHO-CNF is highly efficient in removing U(VI) in the $\mathrm{pH}$ range between 3 and 6 . Gelling of nanofiber hydrogels is observed at $\mathrm{U}(\mathrm{VI})$ concentration of $500 \mathrm{mg} / \mathrm{L}$. Structural changes in the nanofiber network (scanning and transmission electron microscopies) and the surface chemical composition (Xray photoelectron spectroscopy) gave insights on the mechanism of adsorption. The results from batch adsorption experiments are fitted to Langmuir,
\end{abstract}

Electronic supplementary material The online version of this article (https://doi.org/10.1007/s10570-020-02971-8) contains supplementary material, which is available to authorized users.

J. Lehtonen · J. Hassinen ( $\square) \cdot$ L.-S. Johansson ·

O. J. Rojas ( $\square)$

Department of Bioproducts and Biosystems, School of Chemical Engineering, Aalto University, P.O. Box 16300, 00076 Aalto, Espoo, Finland

e-mail: jukka.hassinen@aalto.fi

O. J. Rojas

e-mail: orlando.rojas@aalto.fi

J. Hassinen · R. Mäenpää · O. Ikkala

Department of Applied Physics, School of Science, Aalto

University, P.O. Box 16300, 00076 Aalto, Espoo, Finland
Freundlich, and Sips isotherm models, which indicate a maximum adsorption capacity of $1550 \mathrm{mg} / \mathrm{g}$, the highest value reported so far for any bioadsorbent. Compared to other metals $(\mathrm{Zn}, \mathrm{Mn}$, and $\mathrm{Cu})$ and typical ions present in natural aqueous matrices the phosphorylated nanofibers are shown to be remarkably selective to U(VI). The results suggest a solution for the capture of uranium, which is of interest given its health and toxic impacts when present in aqueous matrices.

Keywords Cellulose nanofibers · Phosphorylated · Uranium $\cdot \mathrm{U}(\mathrm{VI}) \cdot$ Adsorption $\cdot$ Heavy metal
A. A. Kumar - T. Pradeep
DST Unit of Nanoscience (DST UNS) and Thematic Unit of Excellence (TUE), Department of Chemistry, Indian Institute of Technology Madras, Chennai 600036, India
N. Pahimanolis
Betulium Ltd., Tekniikantie 2, 02150 Espoo, Finland
O. J. Rojas
Departments of Chemical and Biological Engineering, Chemistry and Wood Science, The University of British Columbia, 2360 East Mall, Vancouver, BC V6T 1Z3, Canada 


\section{Introduction}

Cellulose has been considered in the development of eco-friendly materials. Particularly, cellulose nanofibers (CNF) have raised interest for their suitability for water purification and heavy metal removal (Voisin et al. 2017). Chemical pretreatments have been used to reduce the energy consumed in $\mathrm{CNF}$ production and to introduce functional groups and charges on its surface. Such pretreatments include TEMPO oxidation, sulfonation, cationization, and phosphorylation (Klemm et al. 2018). The nanoscopic dimensions of CNF result in materials with a high surface area, which enhances interaction with metal ions (Bethke et al. 2018). Consequently, anionic CNF has been studied for removal of several heavy metals (Ma et al. 2012; Liu et al. 2015a). In this application, uranium is highly relevant given its occurrence in natural water as a result of leaching from mineral deposits and industrial processes, e.g., mining waters and nuclear fuel cycle facilities (WHO 2011; Kapnisti et al. 2018). In Finland, for example, concentrations as high as $\sim 15$ $\mathrm{mg} / \mathrm{L}$ have been determined for uranium in water obtained from drilled wells (Asikainen and Kahlos 1979). Uranium removal from these waters is important since it is both hazardous to the environment and toxic to humans. It can cause a kidney failure due to its chemical toxicity, which is typically of greater concern compared to its radioactivity (Kapnisti et al. 2018).

In aqueous media, two stable oxidation states are common for uranium, U(IV) and U(VI) (Aly and Hamza 2013; Xie et al. 2019). Under aerobic conditions, uranium is present in aqueous solutions in its hexavalent form as uranyl ions $\left(\mathrm{UO}_{2}{ }^{2+}\right)$ (Sylwester et al. 2000; Cai et al. 2017; Sarafraz et al. 2017), which predominate in acidic environments (Riegel and Schlitt 2017). As pH increases, hydrolysis of uranyl leads to the formation of $\left(\mathrm{UO}_{2}\right)_{p}(\mathrm{OH})_{q}^{(2 p-q)}$ species (Berto et al. 2012). The uranyl ion can also form various complexes with carbonates present in groundwater (Xie et al. 2019). Due to uranyl complexation, in this manuscript $\mathrm{U}(\mathrm{VI})$ is discussed instead of $\mathrm{UO}_{2}{ }^{2+}$ since we consider conditions where various $\mathrm{UO}_{2}{ }^{2+}$ complexes are present.

The presented information points to the urgent need of technologies that are effective for uranium removal or to prevent the release of toxic concentrations of uranium into the environment (Ghasemi Torkabad et al. 2017). Common techniques used for heavy metal extraction include membrane processes, ion exchange, adsorption, precipitation, and solvent extraction (Chen et al. 2017; Xue et al. 2017; Sarafraz et al. 2017). As a low-cost, easily applicable alternative, adsorption has been considered promising for the removal of U(VI) from aqueous solutions ( $\mathrm{Su}$ et al. 2018). In such application, bioadsorbents are sought after given a number of advantages including costs, geographical availability and the possibility of metal recovery after incineration.

Due to the high affinity of phosphoryl groups to uranium (Zhou et al. 2015), phosphorylated materials such as lignin (Bykov and Ershov 2009), pine wood sawdust (Zhou et al. 2015), graphene oxide (Liu et al. 2015b; Chen et al. 2017), carbon spheres (Yu et al. 2014), chitosan (Sakaguchi et al. 1981; Morsy 2015), cactus fibers (Prodromou and Pashalidis 2013), polyethylene (Shao et al. 2017), zirconium (Um et al. 2007), and mesoporous silica (Sarafraz et al. 2017; Xue et al. 2017), have been demonstrated for uranium removal. Phosphorous-based functional groups act as chelating agents and thus favor binding of uranyl species (Xie et al. 2019). Phosphorylated cellulose nanomaterials have been studied for adsorption of $\mathrm{Fe}^{3+}$ (Božič et al. 2014), $\mathrm{Cu}^{2+}$, and $\mathrm{Ag}^{+}$(Liu et al. 2015a). In addition, CNF bearing bisphosphonate has been shown to be efficient for vanadium removal (Sirviö et al. 2016) while phosphorylated CNF nanopapers have been prepared for the removal of copper (Mautner et al. 2016). The removal of U(VI) has been studied with TEMPO oxidized CNF (TO$\mathrm{CNF}$ ), which achieved an adsorption capacity of $167 \mathrm{mg} / \mathrm{g}$ (Ma et al. 2012), and with carboxycellulose nanofibers prepared by nitro-oxidation, presenting a maximum adsorption capacity of $1470 \mathrm{mg} / \mathrm{g}$ (Sharma et al. 2017). However, to the best of our knowledge, there are no reports on the removal of U(VI) using phosphorylated CNF (PHO-CNF), which is surprising given the prospects indicated for other metals in the earlier studies.

In addition to chemical chelation, surface sorption mechanisms occur at the solid-liquid interface, such as physisorption, complexation, ion exchange, and precipitation, all of which play a crucial role for uranium removal (Xie et al. 2019). In this work, we study the removal of uranium with PHO-CNF using several batch adsorption approaches. Furthermore, we compare the uranium removal efficiency of PHO-CNF 
with different phosphorylation degrees with that determined for native CNF and TO-CNF. The nanocelluloses are characterized by Fourier transform infrared spectroscopy (FT-IR), zeta potential measurements, and transmission electron microscopy (TEM) imaging. Results from the scanning electron microscopy (SEM), TEM, and X-ray photoelectron spectroscopy (XPS) after adsorption are found to give insights into the adsorption mechanism of U(VI). The effect of $\mathrm{pH}$ on the adsorption of $\mathrm{U}(\mathrm{VI})$ and selectivity against other metals are also studied. Adsorption data at $\mathrm{pH} 6$ are fitted to the Langmuir, Freundlich, and Sips isotherm models. The data was found to fit best with the Sips isotherm, demonstrating a maximum adsorption capacity of $1550 \mathrm{mg} / \mathrm{g}$, the highest among the values reported so far for organic adsorbents.

\section{Experimental}

\section{Materials}

Native CNF was produced at Aalto University from bleached birch pulp by a method reported previously (Rajala et al. 2016). PHO-CNF and TO-CNF were obtained from Betulium Oy, Finland. The concentrations of phosphoryl groups provided by the manufacturer were 0.66 and $1 \mathrm{mmol} / \mathrm{g}$ for the $\mathrm{PHO}-\mathrm{CNF}$ samples referred to as $\mathrm{PHO}-\mathrm{CNF}_{0.66}$ and $\mathrm{PHO}-$ $\mathrm{CNF}_{1.00}$, respectively. The concentration of carboxylate groups in TO-CNF was $1 \mathrm{mmol} / \mathrm{g}$. Uranyl acetate, Arsenazo III, ascorbic acid, perchloric acid, and nitric acid were all obtained from Sigma Aldrich. Milli-Q water (Millipore) was used for the preparation of all solutions.

\section{Characterization of $\mathrm{CNF}$}

The electrostatic charge of CNF was determined with a Zetasizer Nano-ZS90 (Malvern), reported as zeta potential, and measured at $\mathrm{pH} 3,5,7$, and 9 (adjusted by using $1 \mathrm{M} \mathrm{HCl}$ and $\mathrm{NaOH}$ ) from $0.05 \mathrm{wt} \% \mathrm{CNF}$ suspensions. The different types of CNF were imaged with a FEI Tecnai 12 TEM operating at $120 \mathrm{kV}$. For sample preparation, $3 \mu \mathrm{L}$ of $0.01 \mathrm{wt} \% \mathrm{CNF}$ suspension was drop casted on a copper grid with an ultrathin carbon support film and the excess solution was blotted with filter paper after 1 min of contact time, followed by drying under ambient conditions.
Thereafter, $3 \mu \mathrm{L}$ of $2 \%$ uranyl acetate was drop casted onto the dried CNF sample in order to stain the sample. The excess solution was blotted with filter paper after 1 min of contact time, followed by drying under ambient conditions. FT-IR spectra of freeze-dried CNF samples were recorded with Nicolet 380 FT-IR Spectrometer using an ATR accessory. The spectra were recorded in the region of $400-4000 \mathrm{~cm}^{-1}$ with $0.5 \mathrm{~cm}^{-1}$ intervals.

\section{Adsorption experiments}

A dry mass of $5 \mathrm{mg}$ of the respective nanocellulose and a total volume of $15 \mathrm{~mL}$ of solution were used in the adsorption experiments, unless otherwise mentioned. Experiments were conducted at room temperature $\left(21-22{ }^{\circ} \mathrm{C}\right)$, which remained stable throughout the experiments. A stock solution of $2000 \mathrm{mg} / \mathrm{L}$ uranyl acetate was used to prepare the solutions. The adsorption isotherm studies were conducted with initial uranium concentrations of 10, 25, 50, 100, 200, 300, 400, and $500 \mathrm{mg} / \mathrm{L}$. Experiments at different $\mathrm{pH}$ and with different CNF types were performed using an initial concentration of $100 \mathrm{mg} / \mathrm{L}$ uranium. For the isotherm study, for the comparison between CNF types, and for the selectivity study, the $\mathrm{pH}$ was adjusted to 6 using $2 \mathrm{M} \mathrm{HCl}$ and $\mathrm{NaOH}$. In all experiments, glass vials were filled with $15 \mathrm{~mL}$ of the suspension containing uranium and $\mathrm{CNF}$ and sonicated to disperse the fibrils in an ultrasonic bath at $37 \mathrm{kHz}$ for $5 \mathrm{~min}$. The samples were then left in a shaker at $200 \mathrm{rpm}$ for $55 \mathrm{~min}$ to reach the equilibrium. After the adsorption process, samples were taken from the solutions and filtered with $0.1 \mu \mathrm{m}$ filters (Whatman). Samples without CNF having similar initial $\mathrm{U}(\mathrm{VI})$ concentrations were used as controls to analyze any possible adsorption of $\mathrm{U}(\mathrm{VI})$ onto the filters. Based on this analysis, the adsorption of uranium onto the filters was found to be negligible. Uranium concentrations were determined spectrophotometrically with Arsenazo III method (Khan et al. 2006) using a microplate reader (Synergy H1) to determine the absorbance of the solutions at $651 \mathrm{~nm}$. Briefly, 25 $\mu \mathrm{L}$ of ascorbic acid (100 g/L), $175 \mu \mathrm{L}$ of Arsenazo III (0.07 w/v\% in $3 \mathrm{M}$ perchloric acid) and $50 \mu \mathrm{L}$ of sample were added to the wells of a microwell plate. If necessary, the samples were diluted to reach a maximum U(VI) concentration of $10 \mathrm{mg} / \mathrm{L}$ before mixing with ascorbic acid and Arsenazo III. For each 
sample, two parallel measurements were conducted with the plate reader and the average of these values reported.

Selectivity experiments were conducted using a concentration of $10 \mathrm{mg} / \mathrm{L}$ for all the metals tested (U, $\mathrm{Zn}, \mathrm{Mn}$, and $\mathrm{Cu}$ ). Other typical ions present in natural waters were also added to the solution according to Table S1 (adapted from Sankar et al. 2013). In the selectivity tests, two different amounts of PHO$\mathrm{CNF}_{1.00}$ were used, $5 \mathrm{mg}$ and $0.25 \mathrm{mg}$ (values given as dry mass in $15 \mathrm{~mL}$ solution). Metal concentrations in the samples used in the selectivity tests were analyzed with inductively coupled plasma mass spectrometry (ICP-MS) (PerkinElmer, NexION 300X). For ICP-MS analysis, the samples were diluted to a maximum concentration of $1 \mathrm{mg} / \mathrm{L}$ and digested with $5 \%$ (vol.) concentrated $\mathrm{HNO}_{3}(68-70 \%)$ before analysis.

The percentage of $\mathrm{U}(\mathrm{VI})$ removed in adsorption studies was calculated based on Eq. (1):

$U$ removal $(\%)=\frac{C_{0}-C_{f}}{C_{0}} \times 100 \%$

and the equilibrium adsorption capacities $\left(q_{e}\right)$ were calculated using Eq. (2):

$q_{e}=\frac{\left(C_{0}-C_{e}\right) V}{m}$

where $C_{0}, C_{f}$, and $C_{e}$ are the initial, final and equilibrium concentrations $(\mathrm{mg} / \mathrm{L})$ of $\mathrm{U}(\mathrm{VI})$, respectively, $V$ is the volume (L) and $m$ is the mass of adsorbent (g) used.

Langmuir, Freundlich, and Sips isotherm models were used for fitting the experimental adsorption data. The Langmuir and Freundlich isotherm models are shown in Eqs. (3) and (4), respectively:

$\frac{C_{e}}{q_{e}}=\frac{C_{e}}{q_{\max }}+\frac{1}{q_{\max } K_{L}}$

$\ln q_{e}=\ln K_{F}+\frac{1}{n} \ln C_{e}$

where $q_{\max }$ is the maximum adsorption capacity (mg/ g) and $K_{L}$ is the Langmuir adsorption constant $(\mathrm{L} / \mathrm{mg})$. $K_{F}$ is the Freundlich isotherm constant and $n$ is the dimensionless heterogeneity factor.
The Sips isotherm model, a combination of the Langmuir and Freundlich isotherms, is expressed as Eq. (5):

$\ln \left(\frac{q_{e}}{q_{m}-q_{e}}\right)=\frac{1}{n} \ln C_{e}+\ln K_{s}$

where $q_{m}$ is the maximum adsorption capacity $(\mathrm{mg} / \mathrm{g}$ ) and $K_{s}$ is the median association constant.

\section{Characterization of $\mathrm{PHO}-\mathrm{CNF}_{1.00}$ after adsorption}

The uranium stock solution was diluted to reach final concentrations of $50,100,250$, and $500 \mathrm{mg} / \mathrm{L}$. After mixing with $\mathrm{PHO}-\mathrm{CNF}_{1.00}$, sonication and shaking as described earlier, a $10 \mu \mathrm{L}$ drop of the PHO-CNF${ }_{1.00}$ uranium suspension was drop casted onto the carbon tape on aluminum stubs and the stubs were placed in a $-80{ }^{\circ} \mathrm{C}$ freezer overnight and freeze dried at $-50{ }^{\circ} \mathrm{C}$. For SEM imaging, the samples were sputter-coated with $3 \mathrm{~nm}$ of platinum-palladium and observed using an acceleration voltage of $1.6 \mathrm{kV}$ with a scanning electron microscope (Zeiss Sigma VP). TEM samples for imaging after $\mathrm{U}(\mathrm{VI})$ adsorption were prepared by drop casting from the suspension with initial U(VI) concentration of $100 \mathrm{mg} / \mathrm{L}$ similarly as described in the characterization section without additional uranium staining.

X-ray photoelectron spectroscopy

Samples for XPS were prepared by vacuum filtration of PHO-CNF ${ }_{1.00}$ onto $0.1 \mu \mathrm{m}$ filters after adsorption of $\mathrm{U}(\mathrm{VI})$ from the initial concentrations of $0,100 \mathrm{mg} / \mathrm{L}$, and $500 \mathrm{mg} / \mathrm{L}$. After vacuum filtration, the filter cakes were frozen at $-80{ }^{\circ} \mathrm{C}$ and freeze-dried to obtain dry films. An electron spectrometer (AXIS Ultra, Kratos Analytical, UK) with monochromatic Al K $\alpha$ irradiation at $100 \mathrm{~W}$ under neutralization was used for the measurements. Three different spots from each film were scanned and elemental surface compositions of the films were determined from low resolution survey scans. High resolution measurements of uranium U 4f, carbon $\mathrm{C} 1 s$ and oxygen $\mathrm{O} 1 s$ were also conducted. Pure cellulose filter paper (Whatman) was used as an in situ reference in all measurements. Data analysis was performed with CasaXPS software, using fitting parameters customized for celluloses and the $\mathrm{C}-\mathrm{O}$ component of the high resolution $\mathrm{C} 1 s$ at $286.7 \mathrm{eV}$ as 
the energy reference for all the spectra (Beamson and Briggs 1992; Johansson and Campbell 2004).

\section{Uranium speciation}

An ion speciation software (PHREEQC) was used to determine the uranyl speciation at $\mathrm{pH}$ range $3-7$, and in the simulated drinking water used for selectivity experiments (Tables S2 and S3). The U(VI) concentration used for the calculations was $100 \mathrm{mg} / \mathrm{L}$.

\section{Results and discussion}

Native and modified CNF

FT-IR was used to confirm the functional groups on the TO-CNF and PHO-CNF (Fig. 1a). The characteristic bands of cellulose were observed in all the samples (broad band at $3340 \mathrm{~cm}^{-1}$ due to $\mathrm{O}-\mathrm{H}$ stretching vibrations, peak at around $1640 \mathrm{~cm}^{-1}$ corresponding to the $\mathrm{O}-\mathrm{H}$ bending of adsorbed water and peaks at around 1030 and $2900 \mathrm{~cm}^{-1}$ corresponding to the $\mathrm{C}-\mathrm{O}$ and $\mathrm{C}-\mathrm{H}$ stretching vibrations, respectively). For the PHO-CNF samples, additional peaks were detected at around $820 \mathrm{~cm}^{-1}, 930 \mathrm{~cm}^{-1}$, and $1230 \mathrm{~cm}^{-1}$ which are assigned to $\mathrm{P}-\mathrm{O}-\mathrm{C}, \mathrm{P}-\mathrm{OH}$, and $\mathrm{P}=\mathrm{O}$ stretching vibrations, respectively (Suflet et al. 2006). For the TO-CNF, a peak at around $1600 \mathrm{~cm}^{-1}$ was detected corresponding to the $\mathrm{C}=\mathrm{O}$ stretching vibration of the $\mathrm{COO}^{-}$group. The zeta potentials of all the CNFs were negative in the $\mathrm{pH}$ range tested (Fig. 1b). The zeta potential values for PHO-CNF and TO-CNF decreased as the $\mathrm{pH}$ increased. This can be explained by the deprotonation of carboxyl or phosphoryl groups. The zeta potentials of the native CNF indicate that it is negatively charged owing to the residual hemicelluloses (containing carboxyl groups) and other impurities originating from the fibers used to prepare the material.

TEM images of the CNFs used in the study are shown in Fig. 2. The images show a clear difference in the size of the native fibrils (Fig. 2a) compared to TO$\mathrm{CNF}$, PHO-CNF $\mathrm{C}_{0.66}$, and $\mathrm{PHO}-\mathrm{CNF}_{1.00}$ (Fig. 2b-d). The native CNF consists of long fibrils, while much shorter fibrils are present inTO-CNF and PHO-CNF, due to the chemical treatment used in the respective preparation.

\section{Adsorption studies}

Batch U(VI) adsorption experiments were conducted with the nanocelluloses. U(VI) adsorption was observed to happen within minutes but to ensure that equilibrium was reached, a contact time of $1 \mathrm{~h}$ was used in all adsorption tests.
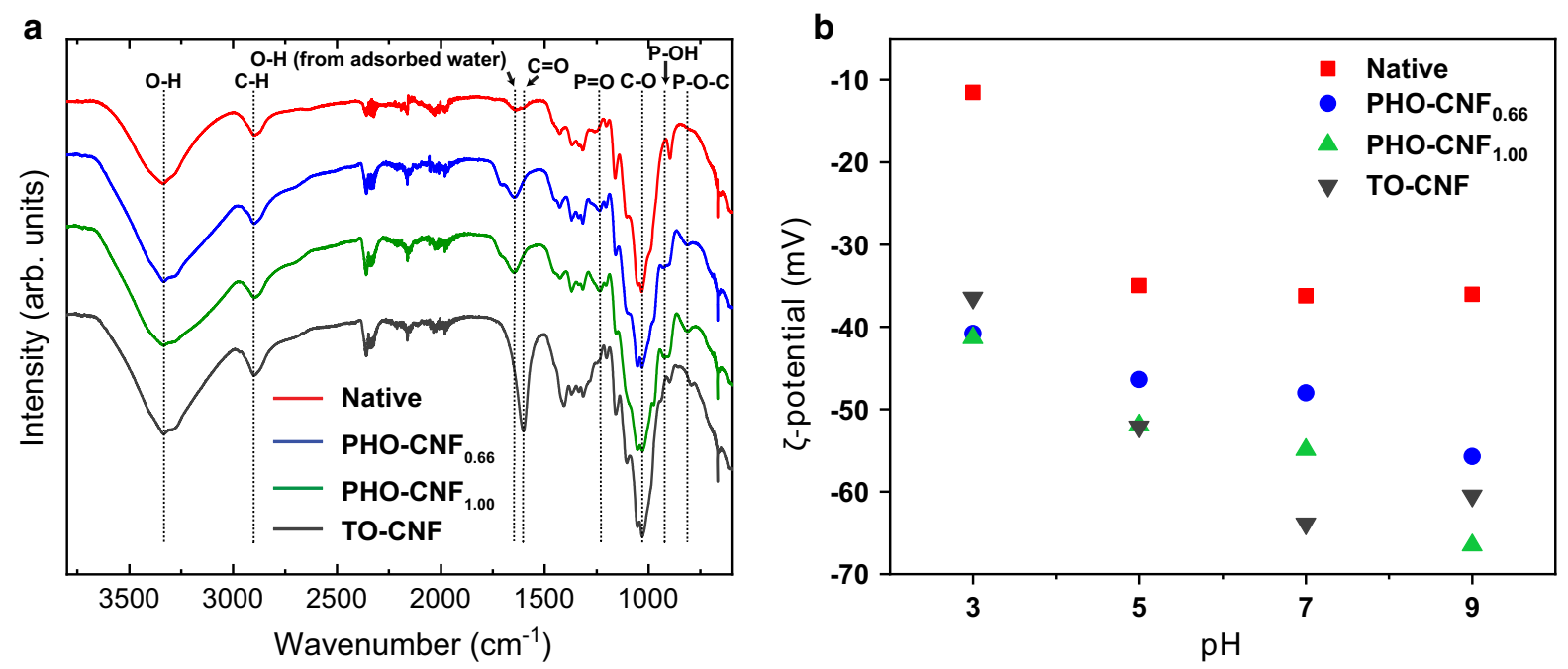

Fig. 1 a FT-IR spectra and $\mathbf{b}$ zeta potentials in the $\mathrm{pH}$ range 3-9 of native $\mathrm{CNF}, \mathrm{PHO}-\mathrm{CNF}_{0.66}, \mathrm{PHO}_{-\mathrm{CNF}}$ 1.00, and TO-CNF 
a

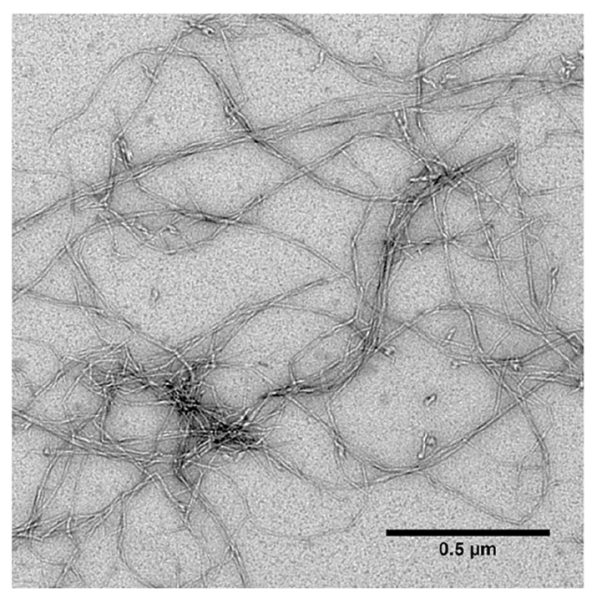

C

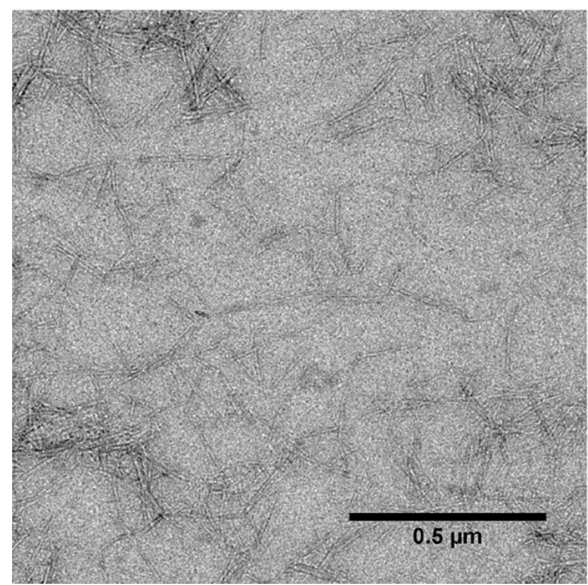

b

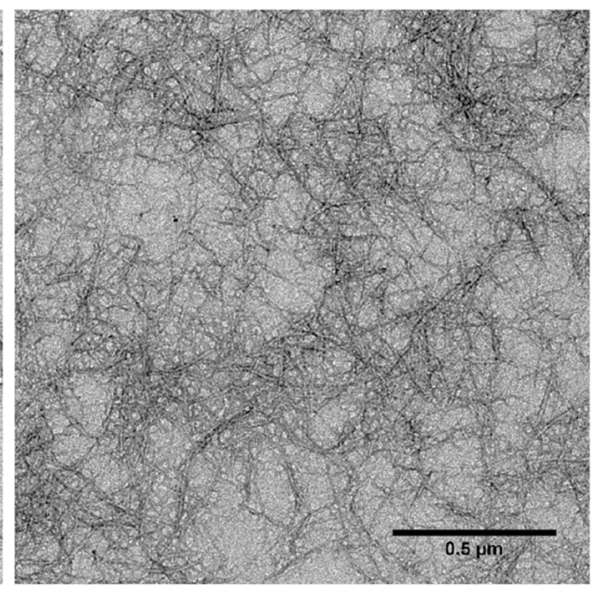

d

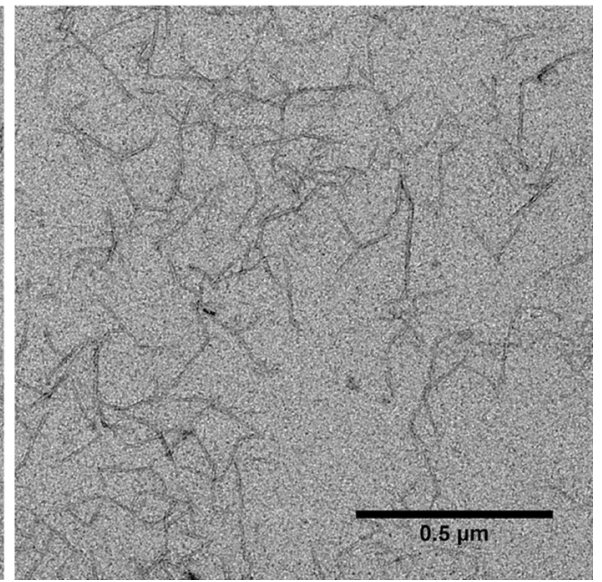

Fig. 2 TEM images of a Native CNF, b TO-CNF, $\mathbf{c}$ PHO-CNF ${ }_{0.66}$, and $\mathbf{d} \mathrm{PHO}-\mathrm{CNF}_{1.00}$

\section{Comparison of adsorption on different types of CNF}

First, the removal of U(VI) with the four different types of CNF was compared using an initial U(VI) concentration of $100 \mathrm{mg} / \mathrm{L}$ (Fig. 3). The results indicate that the PHO-CNF . $_{1.00}$ was the most efficient of the nanocelluloses for uranium removal. The degree of phosphorylation was found to affect the removal of uranium only slightly, since $94 \%$ and $92 \%$ removal was observed with $1 \mathrm{mmol} / \mathrm{g}$ and $0.66 \mathrm{mmol} / \mathrm{g}$ phosphorylation degrees, respectively. However, the removal was significantly higher with $\mathrm{PHO}-\mathrm{CNF}$ in comparison to TO-CNF (77\%) or native CNF (7\%). Based on the results, it can be concluded that the anionic charge of the $\mathrm{CNF}$ is an important factor in the adsorption of U(VI). The removal of U(VI) with PHOCNF and TO-CNF can be mainly attributed to the

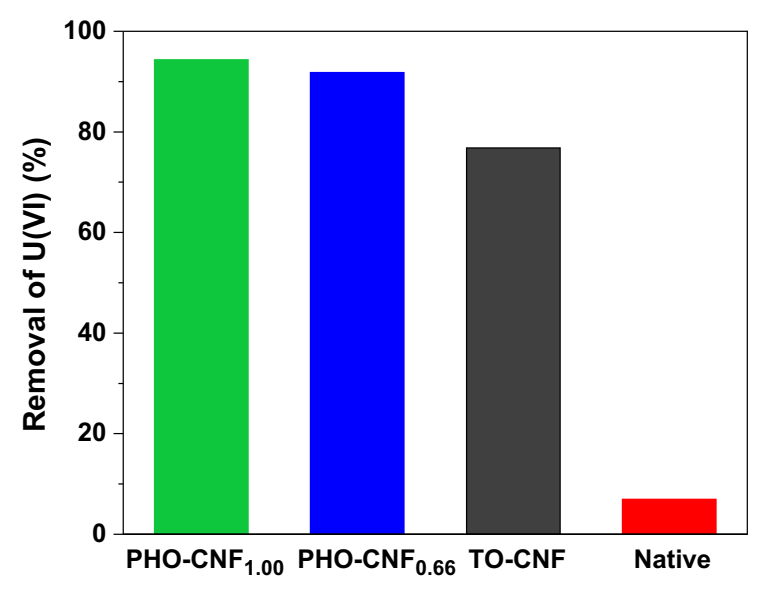

Fig. 3 Removal of U(VI) with PHO-CNF with varying degree of phosphorylation $(1 \mathrm{mmol} / \mathrm{g}$ and $0.66 \mathrm{mmol} / \mathrm{g})$, TEMPO oxidized $\mathrm{CNF}$, and native fibrils 
phosphoryl and carboxyl groups present on the fibrils. In the case of native CNF, the adsorption is most likely explained by the slight negative charge on the fibrils, as confirmed by the zeta potential measurements. However, the higher removal degree achieved with PHO-CNF compared to TO-CNF indicate the higher affinity between phosphoryl groups and U(VI). In addition, the smaller dimensions of the PHO-CNF and TO-CNF compared to native CNF lead to higher surface area, thus enabling higher adsorption capacities. Based on the results of the comparison study, adsorption tests were further continued with PHO$\mathrm{CNF}_{1.00}$.

\section{Characterization of $\mathrm{PHO}-\mathrm{CNF}_{1.00}$ after adsorption}

In batch adsorption experiments, we observed gelling of the nanocellulose at high initial uranium concentrations, e.g. $500 \mathrm{mg} / \mathrm{L}$ (Fig. S1). Thus, the interaction of the fibrils with U(VI) was studied by SEM imaging of the $\mathrm{PHO}-\mathrm{CNF}_{1.00}$ after adsorption using given initial $\mathrm{U}(\mathrm{VI})$ concentrations (Fig. 4). It can be observed that the adsorption at initial uranium concentrations of 50 and $100 \mathrm{mg} / \mathrm{L}$ did not affect the fibrillar morphology and thus the colloidal stability of PHO-CNF 1.00 . However, an initial concentration of $250 \mathrm{mg} / \mathrm{L}$ led to the formation of sheet-like structures, and at $500 \mathrm{mg} / \mathrm{L}$, also precipitate-like material was observed. In order to gain more insights on the formation of these structures, TEM images from samples that used an initial U(VI) concentration of $100 \mathrm{mg} / \mathrm{L}$ were taken after adsorption with PHO-CNF $\mathrm{CN}_{1.00}$ (Fig. 5). The onset of aggregation can be observed in the images, as evidenced by the formation of fibril bundles, ultimately converging to sheet-like structures. It has been reported that due to the linear geometry of uranyl ion, sheet-like or chain-like structures can form upon complexation $(\mathrm{Hu}$ et al. 2018). The individual fibrils observed in the images were surprisingly uniform in width, indicating uniform coverage of phosphoryl groups which led to a spatially homogeneous adsorption of U(VI). Distinctively, the width of the fibrils was measured to be $15 \pm 2 \mathrm{~nm}$ based on image analysis, which is larger than the width measured for the fibrils before adsorption $(12 \pm 2 \mathrm{~nm})$.

These results indicate that crosslinking occurred between the fibrils and U(VI) at high initial U(VI) concentrations, which leads to aggregation of the fibrils. A similar gelling effect has been reported for
CNF containing anionic functional groups and reports are available on the hydrogelation of carboxylated $\mathrm{CNF}$ with monovalent $\left(\mathrm{Ag}^{+}\right)$(Dong et al. 2013a), divalent $\left(\mathrm{Ca}^{2+}, \mathrm{Zn}^{2+}, \mathrm{Cu}^{2+}\right)$, and trivalent cations $\left(\mathrm{Al}^{3+}\right.$ and $\mathrm{Fe}^{3+}$ ) (Dong et al. 2013b). Gelation was suspected to initiate from the screening of repulsive charges caused by cation-carboxylate interactions (Dong et al. 2013b). Moreover, $\mathrm{UO}_{2}{ }^{2+}$ has been found to cause the gelation of TO-CNF. $150 \mathrm{mg} / \mathrm{L}$ was reported as the threshold concentration of $\mathrm{UO}_{2}{ }^{2+}$ for gel formation in a $0.05 \mathrm{wt} \% \mathrm{CNF}$ suspension (Ma et al. 2012). Formation of gels through ionic cross-linking has also been reported with TO-CNF and $\mathrm{Al}^{3+}$ cations (Masruchin et al. 2015). In this study, the gelling effect is likely due to the reduction of electrostatic repulsion between the nanofibers after the adsorption of U(VI).

Results of XPS analysis of PHO-CNF 1.00 after U(VI) adsorption (Fig. 6 and Table S4) confirmed the presence of uranium in its hexavalent state on the fibers, based on the position of the $\mathrm{U}_{4} \mathrm{f}_{7 / 2}$ peak $(382.5 \pm 0.5 \mathrm{eV})$ which was detected after adsorption from both $100 \mathrm{mg} / \mathrm{L}$ and $500 \mathrm{mg} / \mathrm{L}$ samples (Moulder et al. 1995). The XPS results are summarized in Table 1, where the amounts of phosphorous, sodium, and uranium were calculated in relation to the nominal surface cellulose content of the respective sample, in order to remove the effect of adventitious carbon from the results. The nominal surface cellulose content was calculated from the total carbon and the $\mathrm{C}-\mathrm{O}$ component of $\mathrm{C} 1 s$. The decrease in surface cellulose upon increasing uranium content is mainly due to the increase of adventitious carbon (Fig. 6 inset, C-C peak at $285 \mathrm{eV}$ ), indicating changes in the surface energy of cellulose surfaces (Johansson et al. 2011) upon uranium adsorption.

The amount of sodium, which is present as a counterion of phosphoryl groups in the PHO-CNF, was found to decrease as the amount of uranium increased, indicating the occurrence of ion exchange. The amount of phosphorous remained stable in $0 \mathrm{mg} /$ $\mathrm{L}$ and $100 \mathrm{mg} / \mathrm{L}$ samples, and decreased slightly in the $500 \mathrm{mg} / \mathrm{L}$ sample. This is likely due to the increased coverage of uranium on the PHO-CNF${ }_{1.00}$. Highresolution spectra of $\mathrm{O} 1 s$ and $\mathrm{U} 4 \mathrm{f}$ with superimposed spectra from 100 to $500 \mathrm{mg} / \mathrm{L}$ samples are shown in Fig. S2. The similar shape of the superimposed $U 4 f$ spectra of 100 and $500 \mathrm{mg} / \mathrm{L}$ samples clearly indicates that uranium was adsorbed in both cases in a similar chemical form. 

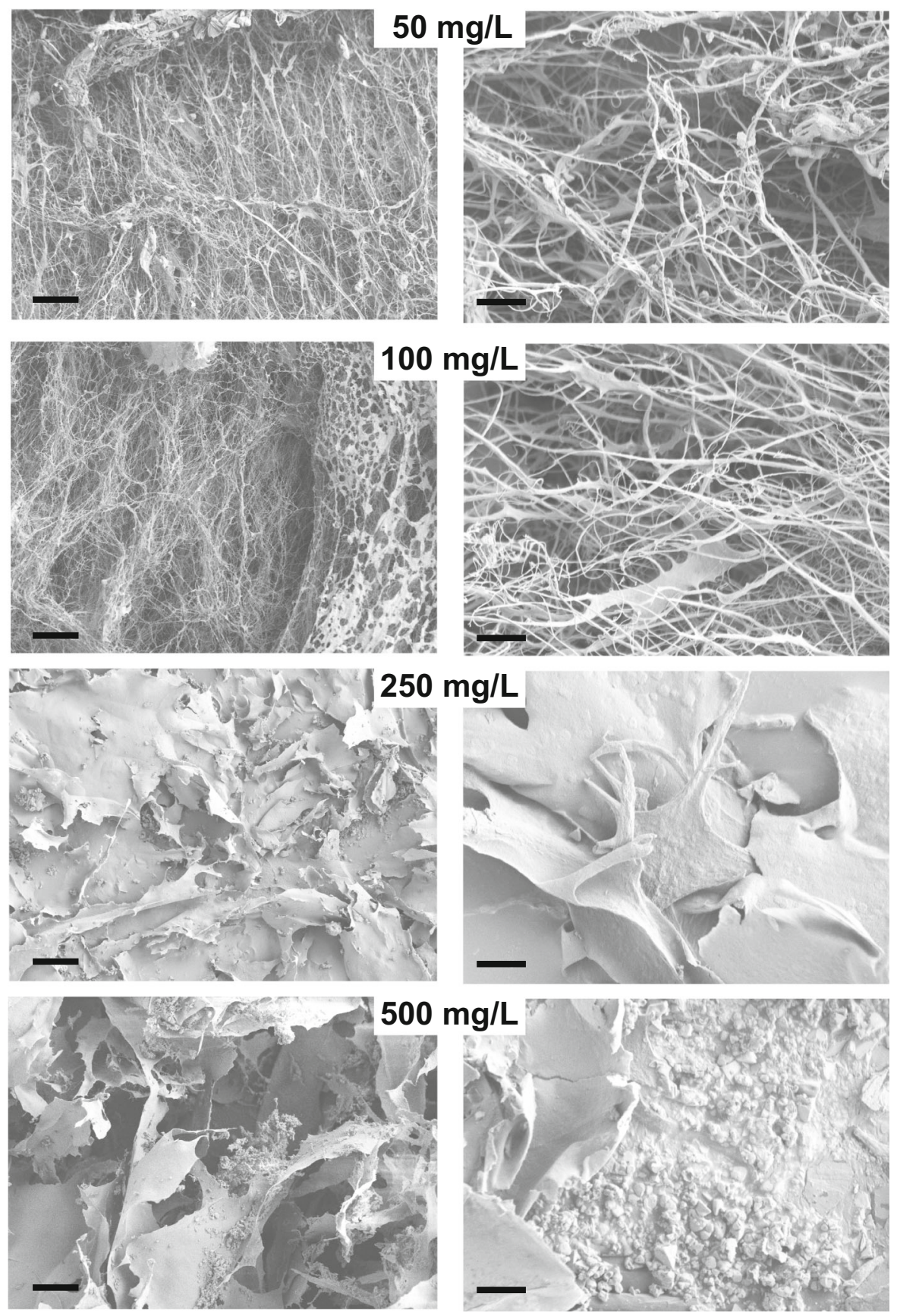

Fig. 4 SEM images of PHO-CNF 1.00 after $1 \mathrm{~h}$ contact with solutions with initial U(VI) concentration of 50, 100, 250, and 500 mg/L. Scale bars are $20 \mu \mathrm{m}$ (left) and $3 \mu \mathrm{m}$ (right)

Apart from elemental information within the topmost few nanometers, XPS survey spectra also yield information on elemental depth distributions within the surface region (Tougaard 1998; Johansson et al. 2004). According to the background shapes of carbon, oxygen, and uranium (see Fig. 6 and Fig. S2), it is clear that uranium species observed in both treated samples were present as islands or open films with similar thicknesses (at least 3-5 nm). 

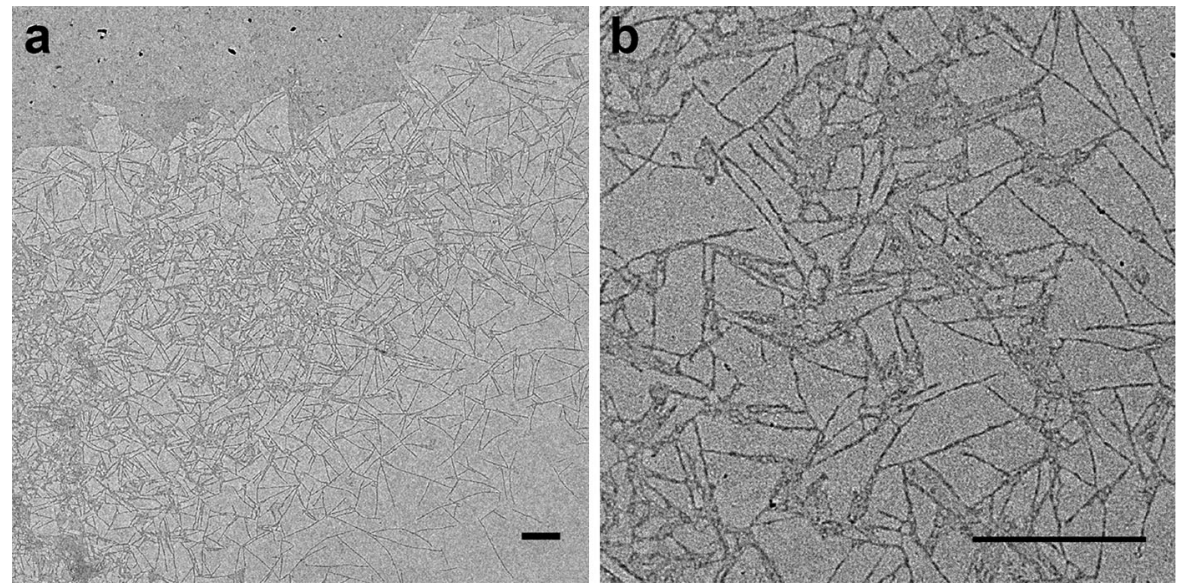

Fig. 5 TEM images showing a overview and $\mathbf{b}$ magnified view of PHO-CNF${ }_{1.00}$ after adsorption of U(VI) from initial U(VI) concentration of $100 \mathrm{mg} / \mathrm{L}$. The scale bars correspond to $1 \mu \mathrm{m}$

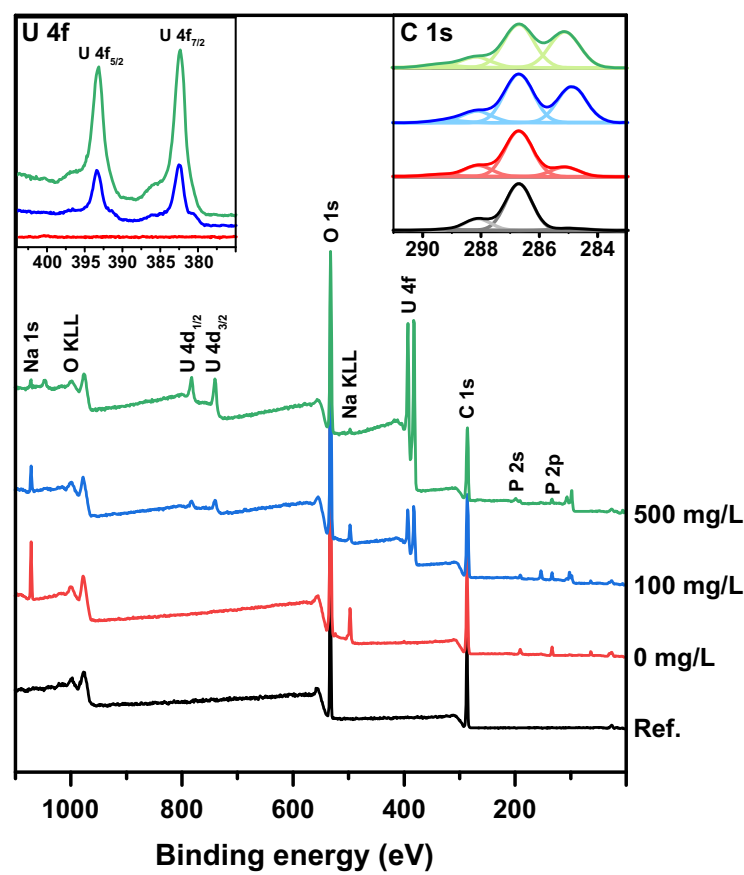

Fig. 6 Survey spectra from XPS measurements of PHO$\mathrm{CNF}_{1.00}$ after $\mathrm{U}(\mathrm{VI})$ adsorption from initial concentrations of 0,100 , and $500 \mathrm{mg} / \mathrm{L}$ and the in situ cellulose reference sample. High-resolution $\mathrm{U} 4 \mathrm{f}$ and $\mathrm{C} 1 s$ spectra are included in the insets, as indicated

\section{Effect of pH on $U(V I)$ adsorption}

Both the adsorbent charge and the speciation of U(VI) are influenced by $\mathrm{pH}$ (Guo et al. 2018). The optimum $\mathrm{pH}$ for heavy metal adsorption is typically acidic, around 4-6. At around neutral $\mathrm{pH}$ and higher, heavy metals often tend to precipitate into hydroxides (Hokkanen et al. 2014). The removal of uranium did not vary significantly in the $\mathrm{pH}$ range $3-6$, as shown in Fig. 7. However, when $\mathrm{pH}$ was increased to 7 , $a \sim 30 \%$ reduction in the uranium removal was observed. $\mathrm{UO}_{2}{ }^{2+}$ speciation is dependent on $\mathrm{pH}$, temperature and composition of the water. At $\mathrm{pH}$ values below 5 , uranium mainly exists as $\mathrm{UO}_{2}{ }^{2+}$ in solution. At $\mathrm{pH}$ values between 5-7, neutral and anionic uranium species can also form in addition to cationic uranyl complexes (Aly and Hamza 2013). At $\mathrm{pH}>6, \mathrm{UO}_{2}{ }^{2+}$ forms complexes in the presence of carbonate causing reduction in U(VI) removal as reported for nanocrystalline titanium dioxide (Wazne et al. 2006) and iron oxyhydroxide (Wazne et al. 2003).

\section{Adsorption capacity}

In order to quantify the maximum adsorption capacity of PHO-NFC $\mathrm{N}_{1.00}$, adsorption experiments were performed with varying initial $\mathrm{U}(\mathrm{VI})$ concentration. The results were fitted to the Langmuir, Freundlich, and Sips adsorption isotherm models (Fig. 8). As expected, the adsorbed uranium amount increases with the equilibrium concentration $\left(C_{e}\right)$ and eventually stabilizes at high $C_{e}$ values. Table S5 shows the isotherm parameters calculated based on Eqs. (3), (4), and (5). Based on the $R^{2}$ values, the Sips isotherm was found to fit best with the experimental data. This model is, in fact, a combination of the Langmuir and Freundlich isotherms. The Langmuir isotherm 
Table 1 Summary of XPS results

\begin{tabular}{lllll}
\hline Sample & $\begin{array}{l}\text { Nominal surface cellulose } \\
\text { content }(\%)\end{array}$ & $\begin{array}{l}\mathrm{P}(\text { at\%) in relation to } \\
\text { cellulose content }(\%)\end{array}$ & $\begin{array}{l}\text { Na (at\%) in relation to } \\
\text { cellulose content }(\%)\end{array}$ & $\begin{array}{l}\mathrm{U}(\text { at } \%) \text { in relation to } \\
\text { cellulose content }(\%)\end{array}$ \\
\hline $\begin{array}{l}\text { Reference } \\
\text { Whatman paper }\end{array}$ & 98 & 0.0 & 0.0 & 0.0 \\
$0 \mathrm{mg} / \mathrm{L}$ & 77 & 4.1 & 3.2 & 0.0 \\
$100 \mathrm{mg} / \mathrm{L}$ & 60 & 4.1 & 1.9 & 2.0 \\
$500 \mathrm{mg} / \mathrm{L}$ & 57 & 3.3 & 0.6 & 6.8 \\
\hline
\end{tabular}

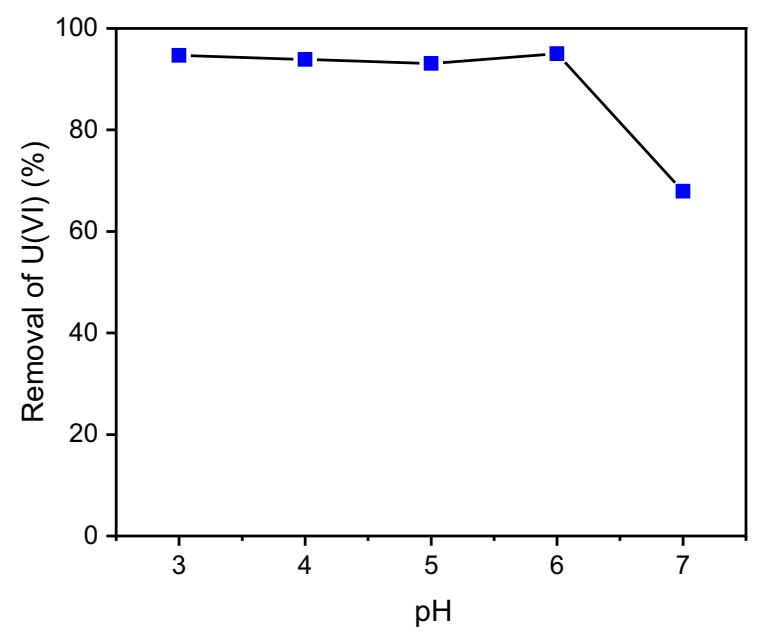

Fig. 7 Effect of $\mathrm{pH}$ on U(VI) removal with $\mathrm{PHO}-\mathrm{CNF}_{1.00}$

assumes monolayer adsorption with a homogeneous surface while the Freundlich isotherm takes into account multilayer adsorption on heterogeneous surfaces (Lombardo and Thielemans 2019). However, in practical terms, the isotherm models do not fully reveal the actual mechanisms of adsorption.

Table 2 presents $q_{\max }$ values of uranium for adsorbents based on different cellulose nanomaterials or phosphorylated biomaterials. Typical maximum adsorption capacities reported for uranium are between 100 and $1000 \mathrm{mg} / \mathrm{g}$. In addition to the high selectivity of the phosphoryl groups to U(VI), the high adsorption capacity achieved in this study is attributed to the high surface area provided by the nanosized fibrils and surface charge density of the PHO-CNF ${ }_{1.00}$.

An estimation of the theoretical maximum adsorption capacity of PHO-CNF 1.00 at $\mathrm{pH} 6$ can be made assuming that all the $\mathrm{U}(\mathrm{VI})$ in the solution occurs as $\left(\mathrm{UO}_{2}\right)_{3}(\mathrm{OH})_{5}^{+}$species. This is reasonable since according to the speciation analysis presented in Table S2,
$96 \%$ of the uranium is in this form. Considering a coordination ratio of $2: 1$ between this species and phosphoryl groups, the maximum adsorption capacity of the PHO-CNF ${ }_{1.00}$ is calculated to be $1430 \mathrm{mg} / \mathrm{g}$, which is very close to the value derived from the Sips isotherm based on the experimental data $(1550 \mathrm{mg} / \mathrm{g})$. Taken any uncertainty on the speciation and the exact form of adsorbed uranium, the results indicate extensive capturing of uranium by PHO-CNF.

\section{Selectivity}

Figure 9 shows the selectivity of $\mathrm{PHO}-\mathrm{CNF}_{1.00}$ to $\mathrm{U}(\mathrm{VI})$ compared to selected divalent metals $(\mathrm{Cu}, \mathrm{Zn}$, and $\mathrm{Mn}$ ) in the presence of other ions typically present in natural waters (Table S1). The removal percentages were found to be in the order of $\mathrm{U}>\mathrm{Cu}>\mathrm{Zn}>\mathrm{Mn}$ with $5 \mathrm{mg}$ PHO-CNF${ }_{1.00}$, corresponding to a metal/ adsorbent weight ratio of 0.03 . When the amount of $\mathrm{CNF}$ was decreased, at a metal/adsorbent weight ratio of 0.6 , the selectivity of the PHO-CNF 1.00 to U(VI) is clearly demonstrated. The results also indicate that high removal rates for uranium could be achieved with PHO-CNF ${ }_{1.00}$ in the presence of competing divalent ions at similar concentrations. Another interesting observation from the results is that the removal of U(VI) increased from 95 to $99 \%$ in the presence of competing ions when the initial uranium concentration was $10 \mathrm{mg} / \mathrm{L}$. A similar result has been reported for uranium removal by magnesium ferrite loaded carbon nanosheets ( $\mathrm{Li}$ et al. 2019). The removal percentage achieved here is comparable to the high removal efficiency reported for uranyl acetate using an amyloid-carbon membrane (99.35\%) (Bolisetty and Mezzenga 2016).

The selectivity of PHO- $\mathrm{CNF}_{1.00}$ to $\mathrm{U}(\mathrm{VI})$ can be explained by the high affinity of the phosphoryl groups 

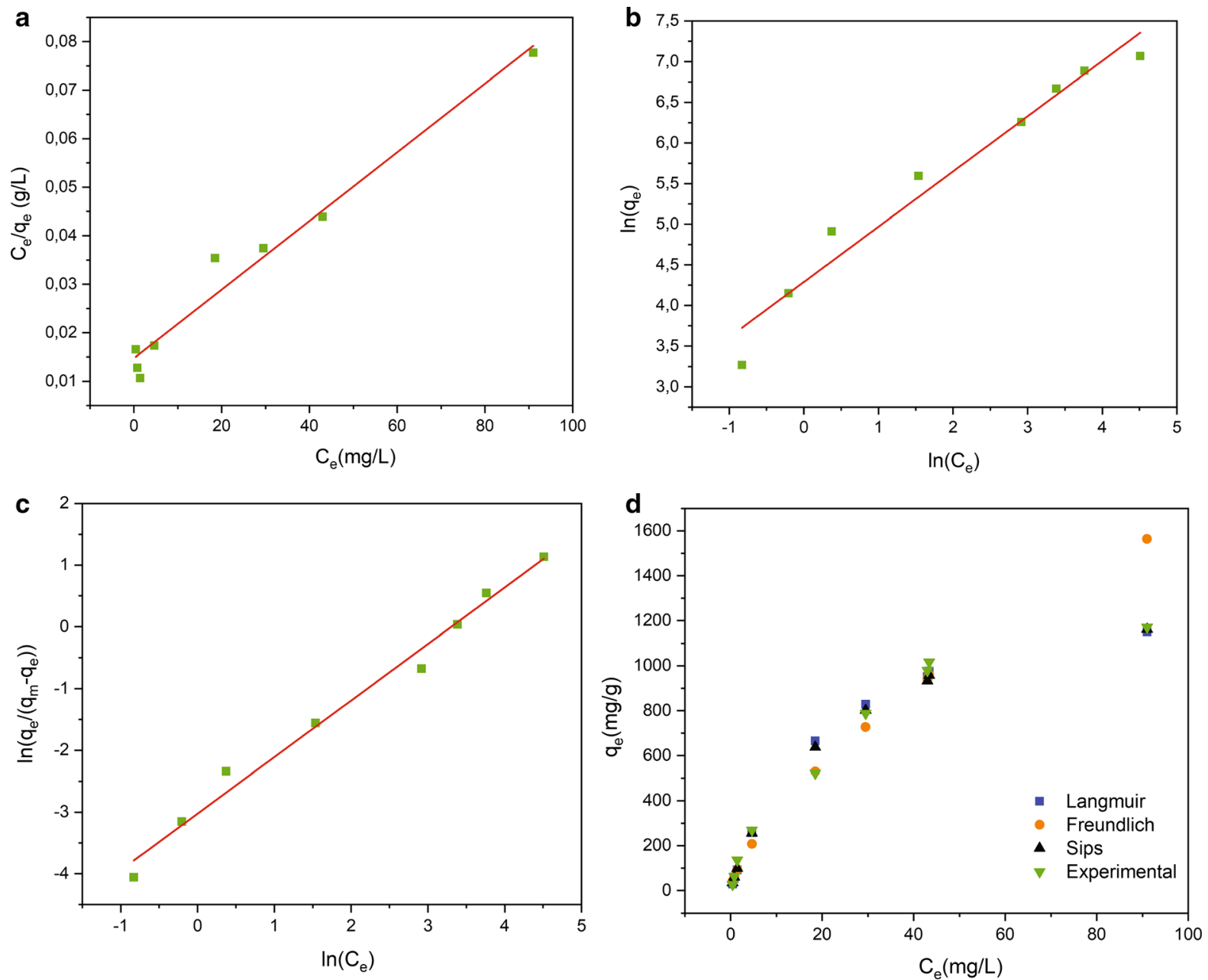

Fig. 8 Effect of initial concentration of U(VI) on adsorption. Adsorption data fitted to a Langmuir isotherm, b Freundlich isotherm, and $\mathbf{c}$ Sips isotherm. $\mathbf{d}$ Adsorption data for $\mathrm{PHO}-\mathrm{CNF}_{1.00}$ compared to the theoretical Langmuir, Freundlich, and Sips isotherm models

Table 2 Maximum adsorption capacity of uranium on different organic adsorbents

\begin{tabular}{lll}
\hline Adsorbent & $\mathrm{q}_{\max }(\mathrm{mg} / \mathrm{g})$ & References \\
\hline TEMPO CNF & $167($ at pH 6.5) & Ma et al. (2012) \\
Phosphorylated cactus fibers & 107 (at pH 4.5) & Prodromou and Pashalidis (2013) \\
Phosphorylated chitosan & $55(\mathrm{pH}$ not reported) & Morsy (2015) \\
Carboxycellulose nanofibers & $1467($ at pH 7) & Sharma et al. (2017) \\
Phosphorylated GO-chitosan & 779 (at pH 5) & Cai et al. (2017) \\
Phosphorylated chitosan CMC & $978($ at pH 5) & Cai et al. (2019) \\
Phosphorylated CNF & $1550($ at pH 6) & This work \\
\hline
\end{tabular}

to uranium. Based on the XPS and batch adsorption studies, it is proposed that the phosphoryl groups play a significant role in the adsorption process. Other factors that can contribute to the high selectivity are the high oxidation state, charge-to-radius ratio and the likelihood of U(VI) to hydrolyze, since solid surfaces typically have a higher affinity to the hydrolyzed species (Cai et al. 2019). Mesoporous silica with phosphonic groups has been found to have high selectivity to uranium against interfering elements 


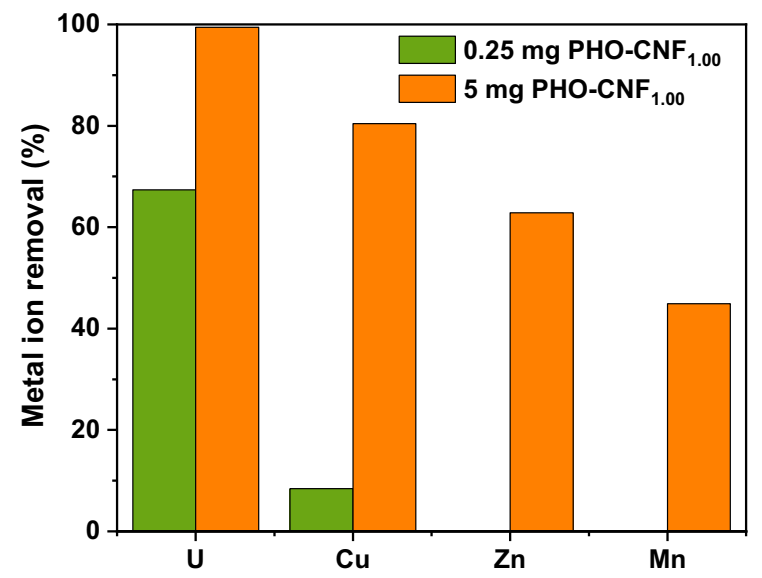

Fig. 9 Selectivity of PHO-CNF${ }_{1.00}$ to U(VI). Removal of heavy metals by $\mathrm{PHO}-\mathrm{CNF}_{1.00}$ was studied from solutions containing $\mathrm{U}, \mathrm{Cu}, \mathrm{Zn}$, and $\mathrm{Mn}$ (initial concentrations were $10 \mathrm{mg} / \mathrm{L})$

such as $\mathrm{As}, \mathrm{K} \mathrm{Ni}, \mathrm{Mo}, \mathrm{Cu}$, and $\mathrm{Pb}$ (Sarafraz et al. 2017). High selectivity of phosphate-functionalized polyethylene towards uranium compared to $\mathrm{Cu}^{2+}$, $\mathrm{Al}^{3+}, \mathrm{Fe}^{3+}$, and $\mathrm{V}^{4+}$ has also been reported (Shao et al. 2017).

\section{Conclusions}

This work demonstrates that PHO-CNF can efficiently remove $\mathrm{U}(\mathrm{VI})$ from aqueous solutions with an unprecedented maximum bioadsorption capacity of $1550 \mathrm{mg} / \mathrm{g}$. Over $90 \%$ removal of U(VI) was achieved in a $\mathrm{pH}$ range of 3-6. The efficiency of PHO-CNF can be attributed to the high surface area, anionic charge and the affinity of the phosphoryl groups to U(VI). The morphology of the substrates was studied after adsorption by SEM, TEM, and XPS, which indicated that U(VI) forms sheet-like aggregates with PHO$\mathrm{CNF}$ at high initial U(VI) concentrations. The high selectivity of the PHO-CNF against other metals and ions present in natural waters is demonstrated, which is critical in application of the material for U(VI) removal. Overall, this study shows that PHO-NFC has great potential as an environmentally friendly bioadsorbent for U(VI) removal from highly contaminated waters.

Acknowledgments Open access funding provided by Aalto University. The Academy of Finland Center of Excellence on Molecular Engineering of Biosynthetic Hybrid Materials
Research (HYBER) and the H2020-ERC-2017-Advanced Grant "BioELCell" (788489) are acknowledged for funding this work. We are also grateful for support of the FinnCERES Materials Bioeconomy Ecosystem. Dr. Joseph Campbell is acknowledged for the XPS measurements. The facilities and technical assistance of Aalto University's OtaNano Nanomicroscopy center (Aalto-NMC) are gratefully acknowledged.

Open Access This article is licensed under a Creative Commons Attribution 4.0 International License, which permits use, sharing, adaptation, distribution and reproduction in any medium or format, as long as you give appropriate credit to the original author(s) and the source, provide a link to the Creative Commons licence, and indicate if changes were made. The images or other third party material in this article are included in the article's Creative Commons licence, unless indicated otherwise in a credit line to the material. If material is not included in the article's Creative Commons licence and your intended use is not permitted by statutory regulation or exceeds the permitted use, you will need to obtain permission directly from the copyright holder. To view a copy of this licence, visit http://creativecommons.org/licenses/by/4.0/.

\section{References}

Aly MM, Hamza MF (2013) A review: studies on uranium removal using different techniques: overview. J Disper Sci Technol 34:182-213. https://doi.org/10.1080/01932691. 2012.657954

Asikainen A, Kahlos H (1979) Anomalously high concentrations of uranium, radium and radon in water from drilled wells in the Helsinki region. Geochim Cosmochim Acta 43:1681-1686. https://doi.org/10.1016/00167037(79)90187-X

Beamson G, Briggs D (1992) High resolution XPS of organic polymers. In: The Scienta ESCA 300 Database. Wiley, Chichester, p 56

Berto S, Crea F, Daniele PG, Gianguzza A, Pettignano A, Sammartano S (2012) Advances in the investigation of dioxouranium(VI) complexes of interest for natural fluids. Coordin Chem Rev 256:63-81. https://doi.org/10.1016/j. ccr.2011.08.015

Bethke K, Palantöken S, Andrei V, Roß M, Raghuwanshi VS, Kettemann F, Greis K, Ingber TTK, Stückrath JB, Valiyaveettil S, Rademann K (2018) Functionalized cellulose for water purification, antimicrobial applications, and sensors. Adv Funct Mater 28(1800409):1-14. https:// doi.org/10.1002/adfm.201800409

Bolisetty S, Mezzenga R (2016) Amyloid-carbon hybrid membranes for universal water purification. Nat Nanotechnol 11:365-372. https://doi.org/10.1038/NNANO.2015.310

Božič M, Liu P, Mathew AP, Kokol V (2014) Enzymatic phosphorylation of cellulose nanofibers to new highly-ions adsorbing, flame-retardant and hydroxyapatite-growth induced natural nanoparticles. Cellulose 21:2713-2726. https://doi.org/10.1007/s10570-014-0281-8 
Bykov GL, Ershov BG (2009) Sorption of uranyl ions on phosphorylated lignin. Radiochemistry 51:292-294. https://doi.org/10.1134/S1066362209030138

Cai Y, Wu C, Liu Z, Zhang L, Chen L, Wang J, Wang X, Yang S, Wang S (2017) Fabrication of a phosphorylated graphene oxide-chitosan composite for highly effective and selective capture of U(VI). Environ Sci Nano 4:1876-1886. https://doi.org/10.1039/c7en00412e

Cai Y, Chen L, Yang S, Xu L, Qin H, Liu Z, Chen L, Wang X, Wang S (2019) Rational synthesis of novel phosphorylated chitosan-carboxymethyl cellulose composite for highly effective decontamination of U(VI). ACS Sustain Chem Eng 7:5393-5403. https://doi.org/10.1021/acssuschemeng. $8 \mathrm{~b} 06416$

Chen H, Wang Y, Zhao W, Xiong G, Cao X, Dai Y, Le Z, Zhang Z, Liu Y (2017) Phosphorylation of graphehe oxide to improve adsorption of $\mathrm{U}(\mathrm{VI})$ from aquaeous solutions. J Radioanal Nucl Chem 313:175-189. https://doi.org/10. 1007/s10967-017-5274-2

Dong H, Snyder JF, Tran DT, Leadore JL (2013a) Hydrogel, aerogel and film of cellulose nanofibrils functionalized with silver nanoparticles. Carbohydr Polym 95:760-767. https://doi.org/10.1016/j.carbpol.2013.03.041

Dong H, Snyder JF, Williams KS, Andzelm JW (2013b) Cationinduced hydrogels of cellulose nano fibrils with tunable moduli. Biomacromolecules 14:3338-3345. https://doi. org/10.1021/bm400993f

Ghasemi Torkabad M, Keshtkar AR, Safdari SJ (2017) Comparison of polyethersulfone and polyamide nanofiltration membranes for uranium removal from aqueous solution. Prog Nucl Energy 94:93-100. https://doi.org/10.1016/j. pnucene.2016.10.005

Guo X, Feng Y, Ma L, Yu J, Jing J, Gao D, Khan AS, Gong H, Zhang Y (2018) Uranyl ion adsorption studies on synthesized phosphoryl functionalised MWCNTs: a mechanistic approach. J Radioanal Nucl Chem 316:397-409. https:// doi.org/10.1007/s10967-018-5761-0

Hokkanen S, Repo E, Suopajärvi T, Liimatainen H, Niinimaa J, Sillanpää M (2014) Adsorption of $\mathrm{Ni}(\mathrm{II}), \mathrm{Cu}(\mathrm{II})$ and Cd(II) from aqueous solutions by amino modified nanostructured microfibrillated cellulose. Cellulose 21:1471-1487. https:// doi.org/10.1007/s10570-014-0240-4

Hu F, Di Z, Lin P, Huang P, Wu M, Jiang F, Hong M (2018) An anionic uranium-base metal-organic framework with ultralarge nanocages for selective dye adsorption. Cryst Gowth Des 18:576-580. https://doi.org/10.1021/acs.cgd. $7 b 01525$

Johansson L-S, Campbell J (2004) Reproducible XPS on biopolymers: cellulose studies. Surf Int Anal 36:1018-1022. https://doi.org/10.1002/sia.1827

Johansson L-S, Campbell J, Koljonen K, Kleen M, Buchert J (2004) On surface distributions in natural cellulosic fibres. Surf Int Anal 36:706-710. https://doi.org/10.1002/sia.1741

Johansson L-S, Tammelin T, Campbell JM, Setälä H, Österberg M (2011) Experimental evidence on medium driven cellulose surface adaptation demonstrated using nanofibrillated cellulose. Soft Matter 7:10917-10924. https://doi. org/10.1039/C1SM06073B

Kapnisti M, Noli F, Misaelides P, Vourlias G, Karfaridis D, Hatzidimitriou A (2018) Enhanced sorption capacities for lead and uranium using titanium phosphates; sorption, kinetics, equilibrium studies and mechanism implication. Chem Eng J 342:184-195. https://doi.org/10.1016/j.cej. 2018.02.066

Khan MH, Warwick P, Evans N (2006) Spectrophotometric determination of uranium with arsenazo-III in perchloric acid. Chemosphere 63:1165-1169. https://doi.org/10. 1016/j.chemosphere.2005.09.060

Klemm D, Cranston ED, Fischer D, Gama M, Kedzior SA, Kralisch D, Kramer F, Kondo T, Lindström T, Nietzsche S, Petzold-Welcke K, Rauchfuß F (2018) Nanocellulose as a natural source for groundbreaking applications in materials science: today's state. Mater Today 21:720-748. https:// doi.org/10.1016/j.mattod.2018.02.001

Li X, Li Y, Wu Q, Zhang M, Guo X, Li X, Ma L, Li S (2019) Ultrahigh uranium uptake by magnetic magnesium ferrite loaded hydrothermal carbon nanosheets under acidic condition. Chem Eng J 365:70-79. https://doi.org/10.1016/j. cej.2019.02.002

Liu P, Borrell PF, Božič M, Kokol V, Oksman K, Mathew AJ (2015a) Nanocelluloses and their phosphorylated derivatives for selective adsorption of $\mathrm{Ag}^{+}, \mathrm{Cu}^{2+}$ and $\mathrm{Fe}^{3+}$ from industrial effluents. J Hazard Mater 294:177-185. https:// doi.org/10.1016/j.jhazmat.2015.04.001

Liu X, Li J, Wang X, Chen C, Wang X (2015b) High performance of phosphate-functionalized graphene oxide for the selective adsorption of U(VI) from acidic solution. J Nucl Mater 466:56-64. https://doi.org/10.1016/j.jnucmat.2015. 07.027

Lombardo S, Thielemans W (2019) Thermodynamics of adsorption on nanocellulose surfaces. Cellulose 26:249-279. https://doi.org/10.1007/s10570-018-02239-2

Ma H, Hsiao BS, Chu B (2012) Ultrafine cellulose nanofibers as efficient adsorbents for removal of $\mathrm{UO}_{2}{ }^{2+}$ in water. ACS Macro Lett 1:213-216. https://doi.org/10.1021/ mz200047q

Masruchin N, Park B, Causin V, Um IC (2015) Characteristics of TEMPO-oxidized cellulose fibril-based hydrogels induced by cationic ions and their properties. Cellulose 22:1993-2010. https://doi.org/10.1007/s10570-015-06240

Mautner A, Maples HA, Kobkeatthawin T, Kokol V, Karim Z, Li K, Bismarck A (2016) Phosphorylated nanocellulose papers for copper adsorption from aqueous solutions. Int $\mathbf{J}$ Environ Sci Technol 13:1861-1872. https://doi.org/10. 1007/s13762-016-1026-Z

Morsy AMA (2015) Adsorptive removal of uranium ions from liquid waste solutions by phosphorylated chitosan. Environ Technol Innov 4:299-310. https://doi.org/10.1016/j.eti. 2015.10.002

Moulder JF, Stickle WF, Sobol PE, Bomben KD (1995) Handbook of X-ray photoelectron spectroscopy: a reference book of standard spectra for identification and interpretation of XPS data. Perkin-Elmer Corp., Physical Electronics Division, Eden Prairie

Prodromou M, Pashalidis I (2013) Uranium adsorption by nontreated and chemically modified cactus fibres in aqueous solutions. J Radioanal Nucl Chem 298:1587-1595. https:// doi.org/10.1007/s10967-013-2565-0

Rajala S, Siponkoski T, Sarlin E, Mettänen M, Vuoriluoto M, Pammo A, Juuti J, Rojas OJ, Franssila S, Tuukkanen S (2016) Cellulose nanofibril film as a piezoelectric sensor 
material. ACS Appl Mater Interfaces 8:15607-15614. https://doi.org/10.1021/acsami.6b03597

Riegel M, Schlitt V (2017) Sorption dynamics of uranium onto anion exchangers. Water 9(268):1-17. https://doi.org/10. 3390/w9040268

Sakaguchi T, Horikoshi T, Nakajima A (1981) Adsorption of uranium by chitin phosphate and chitosan phosphate. Agric Biol Chem 45:2191-2195. https://doi.org/10.1080/ 00021369.1981 .10864862

Sankar MU, Aigal S, Maliyekkal SM, Chaudhary A, Anshup KA, Chaudhari K, Pradeep T (2013) Biopolymer-reinforced synthetic granular nanocomposites for affordable point-of-use water purification. Proc Natl Acad Sci 110:8459-8464. https://doi.org/10.1073/pnas.1220222110

Sarafraz H, Minuchehr A, Alahyarizadeh G, Rahimi Z (2017) Synthesis of enhanced phosphonic functional groups mesoporous silica for uranium selective adsorption from aqueous solutions. Sci Rep 7:1-12. https://doi.org/10. 1038/s41598-017-11993-5

Shao D, Li Y, Wang X, Hu S, Wen J, Xiong J, Asiri AM, Marwani HM (2017) Phosphate-functionalized polyethylene with high adsorption of uranium(VI). ACS Omega 2:3267-3275. https://doi.org/10.1021/acsomega. $7 \mathrm{~b} 00375$

Sharma PR, Chattopadhyay A, Sharma SK, Hsiao BS (2017) Efficient removal of $\mathrm{UO}_{2}{ }^{2+}$ from water using carboxycellulose nanofibers prepared by the nitro-oxidation method. Ind Eng Chem Res 56:13885-13893. https://doi.org/10. 1021/acs.iecr.7b03659

Sirviö JA, Hasa T, Leiviskä T, Liimatainen H, Hormi O (2016) Bisphosphonate nanocellulose in the removal of vana$\operatorname{dium}(V)$ from water. Cellulose 23:689-697. https://doi. org/10.1007/s10570-015-0819-4

Su S, Liu Q, Liu J, Zhang H, Li R, Jing X, Wang J (2018) Functionalized sugarcane bagasse for U(VI) adsorption from acid and alkaline conditions. Sci Rep 8:1-10. https:// doi.org/10.1038/s41598-017-18698-9

Suflet DM, Chitanu GC, Popa VI (2006) Phosphorylation of polysaccharides: new results on synthesis and characterisation of phosphorylated cellulose. React Funct Polym 66:1240-1249. https://doi.org/10.1016/j.reactfunctpolym. 2006.03.006

Sylwester ER, Hudson EA, Allen PG (2000) The structure of uranium(VI) sorption complexes on silica, alumina, and montmorillonite. Geochim Cosmochim Acta 64:2431-2438. https://doi.org/10.1016/S00167037(00)00376-8
Tougaard S (1998) Accuracy of the non-destructive surface nanostructure quantification technique based on analysis of the XPS or AES peak shape. Surf Int Anal 24:249-269. https://doi.org/10.1002/(SICI)1096-9918(199804)26: 4<249::AID-SIA368>3.0.CO;2-A

Um W, Mattigod S, Serne RJ, Fryxell GE, Kim DH, Troyer LD (2007) Synthesis of nanoporous zirconium oxophosphate and application for removal of U(VI). Water Res 41:3217-3226. https://doi.org/10.1016/j.watres.2007.05. 030

Voisin H, Bergström L, Liu P, Mathew AP (2017) Nanocellulose-based materials for water purification. Nanomaterials 7:57. https://doi.org/10.3390/nano7030057

Wazne M, Korfiatis GP, Meng X (2003) Carbonate effects on hexavalent uranium adsorption by iron oxyhydroxide. Environ Sci Technol 37:3619-3624. https://doi.org/10. 1021/es034166m

Wazne M, Meng X, Korfiatis GP, Christodoulatos C (2006) Carbonate effects on hexavalent uranium removal from water by nanocrystalline titanium dioxide. J Hazard Mater 136:47-52. https://doi.org/10.1016/j.jhazmat.2005.11.010

World Health Organization WHO (2011) Guidelines for drinking-water quality, 4th edn

Xie Y, Chen C, Ren X, Wang X, Wang H, Wang X (2019) Emerging natural and tailored materials for uranium-contaminated water treatment and environmental remediation. Prog Mater Sci 103:180-234. https://doi.org/10.1016/j. pmatsci.2019.01.005

Xue G, Feng Y, Ma L, Gao D, Jing J, Yu J, Sun H, Gong H, Zhang Y (2017) Phosphoryl functionalized mesoporous silica for uranium adsorption. Appl Surf Sci 402:53-60. https://doi.org/10.1016/j.apsusc.2017.01.050

Yu XF, Liu YH, Zhou ZW, Xiong GX, Cao XH, Li M, Zhang ZB (2014) Adsorptive removal of U(VI) from aqueous solution by hydrothermal carbon spheres with phosphate group. J Radioanal Nucl Chem 300:1235-1244. https://doi. org/10.1007/s10967-014-3081-6

Zhou L, Huang Z, Luo T, Jia Y, Liu Z, Adesina AA (2015) Biosorption of uranium(VI) from aqueous solution using phosphate-modified pine wood sawdust. J Radioanal Nucl Chem 303:1917-1925. https://doi.org/10.1007/s10967014-3725-6

Publisher's Note Springer Nature remains neutral with regard to jurisdictional claims in published maps and institutional affiliations. 